\title{
A SALA PARPALLÓ Y SU CONTRIBUCIÓN A LA FOTOGRAFÍA EN VALENCIA (1980-1995)
}

RAQUEL BAIXAULI

Universitat de València

Raquel.Baixauli@uv.es

ESTHER GONZÁLEZ GEA

Universitat de València esther.gonzalez-gea@uv.es

\begin{abstract}
Resumen: La historia de la fotografía ha reservado una parte importante a plasmar la lucha por lograr la consideración artística del medio. Sin embargo, poco se han tenido en cuenta los intereses de aquellos quienes escriben los discursos que trascienden, y más en un ámbito de carácter local. El objetivo de este artículo es perfilar un panorama general sobre el horizonte expositivo valenciano en el ámbito de lo fotográfico, tomando como caso particular la Sala Parpalló, espacio inaugurado en 1980 y dirigido por Artur Heras hasta 1995. Para ello, partiremos de un contexto concreto con el objetivo de llegar a comprender la importancia que esta sala tuvo a nivel nacional, consolidándose como pionera en muchos de sus aspectos.
\end{abstract}

Palabras clave: Fotografía / historia de la fotografía / Sala Parpalló / muestras fotográficas / Valencia.

\section{SALA PARPALLÓ AND ITS CONTRIBUTION TO PHOTOGRAPHY IN VALENCIA (1980-1995)}

Abstract: The history of photography has reserved an important part to capture the fight to achieve the artistic consideration of the photographic medium. However, the interests of those who write the history of the photography that transcend were taken little account, even less in a local scope. The aim of this paper is to approach a general overview about the Valencian exhibition horizon in the field of photography, taking as case of study the Sala Parpalló, a space opened in 1980 which was directed by Artur Heras until 1995. For this, we depart from a specific context to understand the importance of this space at national level, being it pioneer in several aspects.

Key words: Photography / history of photography / Sala Parpalló / photographic exhibitions / Valencia.

\section{Breve historia de la Sala Párpalló}

En plena efervescencia democrática, y en un ambiente cultural cargado de entusiasmo, a principios de 1980 la Diputación Provincial de Valencia recuperaba el antiguo teatro del Patronato de la Juventud Obrera, rebautizado como Teatro Escalante, a la par que inauguraba un espacio dedicado a la exposición de arte contemporáneo, que dependería orgánicamente del área de cultura de dicha institución. ${ }^{1}$
Como bien afirma Artur Heras, quien dirigió este espacio desde su apertura en 1980 hasta el año 1995, la Sala Parpalló no fue un proyecto cerrado al inicio, pues respondía a las inquietudes y a la aparición de nuevos valores por parte de la creciente sociedad. ${ }^{2}$ Con el objetivo de normalizar el arte moderno en Valencia, la Parpalló que gestó Heras junto con un equipo modesto -entre quienes estaban Vicente Todolí- llegó a consolidarse como un

\footnotetext{
* Fecha de recepción: 15 de abril de 2019 / Fecha de aceptación: 20 de noviembre de 2020.

1 RAUSELL KÖSTER, Pau, 1999, p. 196.

2 LUCAS, Pascual, 1990, p. 84.
} 


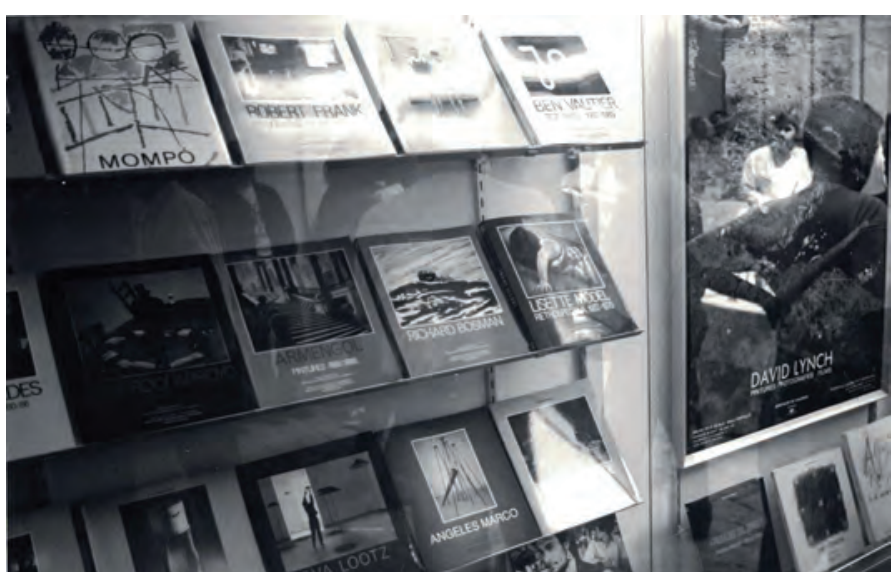

Fig. 1. José García Poveda 'El Flaco'. Expositor con algunos de los libros que forman parte de la Colección Imagen. 1992. Archivo de Artur Heras.

referente nacional por las novedades incorporadas al discurso expositivo. Frente al anquilosamiento que caracterizaba las mentalidades anteriores, sin contar con las iniciativas privadas y algunas excepciones públicas, en este espacio oficial podían empezar a contemplarse discursos y medios que no habían sido incluidos -o que habían sido frenados por las vicisitudes de la dictadura- en el discurso expositivo previo de la cultura hegemónica, como la fotografía y el vídeo. ${ }^{3}$

Siguiendo a Heras, entre los referentes más próximos tomados en consideración en el momento de apertura de la Sala Parpalló cabe señalar el Museo de Arte Abstracto de Cuenca, el Museo de Vilafamés o los fondos de la colección privada de Eusebio Sempere, instalados entonces en la Casa de La Asegurada de Alicante.

Entre las líneas expositivas que regían la programación, se encontraban tres diferenciadas. A grandes rasgos, pueden distinguirse aquellas exposiciones de artistas significantes en el momento en que la sala estaba activa, y cuya obra muchas veces no había podido ser antes contemplada en nuestro país; exposiciones temáticas sobre tendencias o artistas que, aun siendo conocidos, no habían sido objeto de una muestra crítica en territorio nacional; $y$, finalmente, las muestras de artistas jóvenes impulsadas por la creación en 1981 de los premios y becas Alfons Roig. ${ }^{4}$

Desde muy pronto, las exposiciones se acompañaron de actividades didácticas y de publicaciones en forma de catálogos y carteles que contribuyeron a la labor de difusión. Especialmente destacable es la promoción de la Colección Imagen, editada por la Sala Parpalló en colaboración con la Institución Alfons el Magnànim. Inaugurada con la edición, en 1983, del catálogo dedicado a la muestra del fotógrafo Walker Evans se convirtió, junto a la colección Photo Poche editada por Robert Delpire (1926-2017) bajo el auspicio del Centre National de la Photographie de París, en un referente para los y las fotógrafas de esas generaciones. Además, la Sala Parpalló también editó, junto con el colectivo de estudios de comunicación artística de la Universitat de València, la hoy desaparecida revista Reüll (1983-1986).

La primera Sala Parpalló se asentó, tal como se ha apuntado, anexa al Teatro Escalante, en calle de Landerer, y abrió sus puertas al público con una exposición sobre Joan Miró. En 1991, con motivo de la restauración del Palau dels Scala, este espacio se adhirió al proyecto y su programación y actividades empezaron a depender de la Sala Parpalló. ${ }^{5}$ Aunque de manera modesta, este espacio presentó propuestas interesantes que paulatinamente fueron avaladas por el público, ocupándose dicho espacio hasta 1995, momento en que Artur Heras fue destituido con una saña innecesaria $-y$, a propósito, difamado a través de ciertos medios de comunicación del momento-, y en que la sala se trasladó al Centre Cultural La Beneficiència, manteniéndose allí hasta 2001.

\section{En 1998, Pablo Ramírez escribía lo siguiente:}

Algún día habrá que estudiar las relaciones, intercambios y deudas recíprocas que durante este período comenzaron a producirse entre las galerías y los nuevos espacios institucionales que como hongos comenzaron a proliferar por toda la geografía nacional, configurando el punto de partida de la situación que vivimos hoy. ${ }^{6}$

\footnotetext{
3 LÓPEZ, José Alberto (dir.), 1993, p. 122-123.
}

4 En 1981 se convocó la primera edición de los premios Alfons Roig, destinados a artistas plásticos nacidos en la Comunidad Valenciana o formados en la Facultad de Bellas Artes. En 1982 se hizo la primera exposición con las obras de los primeros premiados. DE LA CALLE, Román, 2005, p. 11; DE LA CALLE, Román, 2006, p. 177. Vinculados a la andadura de la primera Sala Parpalló, como afirma Laura Silvestre, el objetivo de estos premios fue reconocer, respaldar y promocionar a artistas emergentes crecidos artísticamente en la ciudad de Valencia. SILVESTRE GARCÍA, Laura, 2012, p. 38-39.

5 LÓPEZ, José Alberto (dir.), 1993, p. 123.

6 RAMÍREZ, Pablo, 1998, p. 13. 
Recuperando las palabras escritas por Ramírez a finales del siglo pasado, era necesario poner en relación la apertura de espacios como la Sala Parpalló con la amalgama de opciones que empezaron a gestarse y a ver la luz en la ciudad de Valencia, así como las decisiones institucionales en materia de innovación, centradas en los distintos medios que integra el arte contemporáneo, entre ellos el fotográfico. Tal como puede intuirse, la Sala Parpalló se consolidó, fundamentalmente durante la década de los años 80 , como un espacio pionero por incorporar a su programación autores y autoras, medios y discursos nunca antes vistos en la ciudad, que cambiaron el devenir de la misma en los años venideros.

\section{Muestras fotográficas en la Sala Parpalló (1980-1995)}

Siguiendo la máxima que entiende que la fotografía atraviesa todos los procesos históricos, la Sala Parpalló nace con una voluntad clara de incluir lo fotográfico en sus filas como artefacto cultural que convive y conversa con otros medios artísticos de vanguardia. Este epígrafe tiene como objetivo servir de aproximación al panorama expositivo valenciano, mereciendo especial atención las muestras fotográficas celebradas entre los años 1980 y 1995 en la Sala Parpalló, y teniendo en cuenta la naturaleza de las mismas. Lejos de querer enumerar cada una de ellas y la repercusión de las mismas en su momento -pues este trabajo lo llevó a cabo, fundamentalmente, Artur Heras cuando aún gestionaba el espacio-, ${ }^{7}$ optamos por trazar un panorama general en el que prácticamente la historia del arte no ha ahondado, para que sirva como precedente a aquellos investigadores e investigadoras que deseen retomar y enriquecer el tema.

Curiosamente, y tal como se ha mencionado anteriormente, la Sala Parpalló no abrió sus puertas al público con una muestra de fotografía, sino con una exposición sobre Joan Miró (1893-1983). Sin embargo, poco después, en el mismo año 1980, se presentó la primera exposición producida y gestionada por la propia sala, una muestra colectiva e itinerante que sí versaba sobre lo fotográfico y ponía en valor un patrimonio propio: Aspectes de la fotografia al País Valencià.
Esta iniciativa "fue el primer intento por ofrecer una mirada acerca de la Fotografía como medio de expresión", ${ }^{8}$ y su importancia y relevancia reside en que fue la primera exposición que pretendía recoger autores valencianos diseminados geográficamente por el territorio nacional y agruparlos en torno a una muestra panorámica que reflejara la situación de la fotografía en ese momento. Por primera vez en mucho tiempo, alguien se preguntaba de manera fundada y crítica acerca de los interrogantes del nuevo medio a nivel nacional. En concreto, la incursión de Aspectes de la fotografia al País Valencià supuso, por un lado, una mirada fresca a una problemática clásica, y por otro, un peldaño más a la configuración de una cartografía de la fotografía nacional desde un punto geográfico considerado más local.

La intención de mostrar la difusión del panorama fotográfico de un país o zona geográfica concreta no fue, sin embargo, algo aislado en la gestión de la Sala Parpalló, y a lo largo de su recorrido, desde 1980 a 1995, encontramos muestras regidas por el mismo patrón -la exposición sobre Fotografia catalana con motivo de las I Jornades Fotogràfiques a València (1984), Fotografía japonesa contemporánea (1986), Joven fotografía europea (1989), o Fotografía soviética, 1940-1991 (1993)-.

Además de aquellas exhibiciones que mostraban la situación de la fotografía en un contexto geográfico determinado, hubo también exposiciones que mostraron la visión de un tema específico -Fotografia i llibertat d'expressió (1981), De nit (1989), Cuerpos, memorias: Nobuyoshi Araki y Larry Clark (1994)-. Sin embargo, la línea expositiva en el ámbito fotográfico que más predominó fue aquella que comprendía muestras monográficas de autores de prestigio, fundamentalmente desde el ámbito internacional, cuya obra en muchos casos no había podido ser contemplada antes en nuestro país. ${ }^{9}$

La de Walker Evans -Walker Evans, 1903-1975 (1983) - fue una de las más tempranas muestras fotográficas de este autor en España, aunque las estadísticas en cuanto a la asistencia de público dejan entrever los prejuicios y desinformación en cuanto al nuevo medio expuesto. ${ }^{10}$ Un aspecto importante

\footnotetext{
7 HERAS, Artur, 1991.

8 CANCER MATINERO, José Ramón, 2013, p. 105.

9 Manuel García afirma que la fotografía de talante periodístico, documentalista o de aspecto más innovador no se exhibió en la Sala Parpalló sino que, tal como se desarrollará en el texto, el criterio de difusión entre los años 1980 y 1995 estuvo marcado por la presentación de fotógrafos que gozaban de renombre en la historia de la fotografía y cuya obra, generalmente, no había sido exhibida con anterioridad en territorio nacional. GARCíA, Manuel, 1998, p. 8-9.

10 HERAS, Artur, 1991, p. 21. En este trabajo no publicado, perteneciente al archivo del propio artista, encontramos un dossier de tablas con las estadísticas del público visitante durante los años 1980 a 1991, así como un anexo de referencias en prensa sobre lo más relevante publicado hasta entonces en los medios.
} 


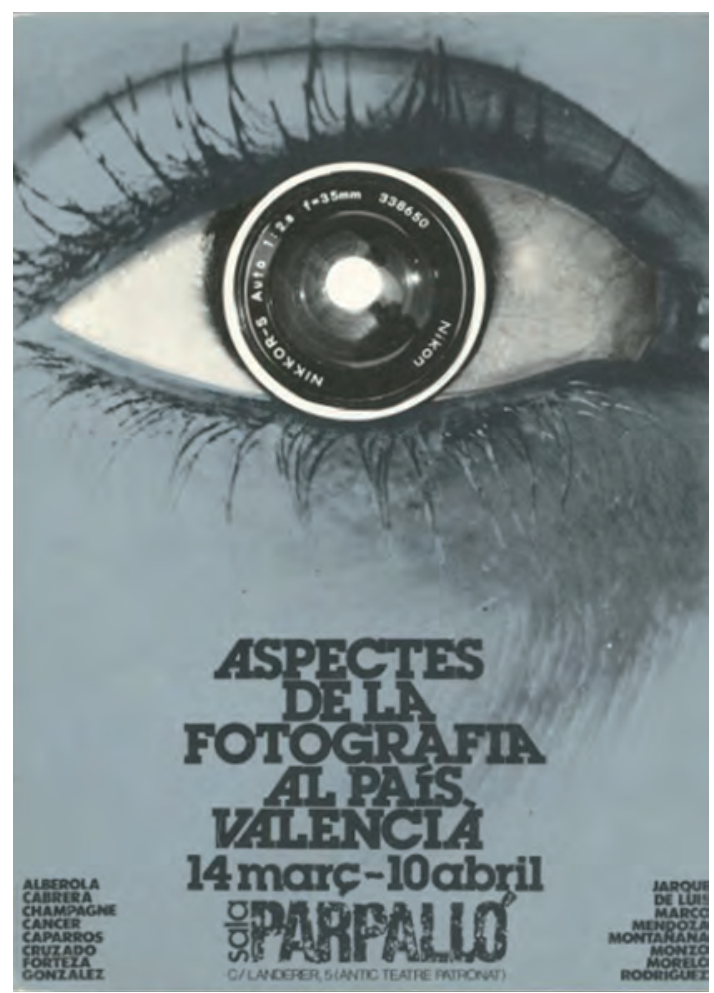

Fig. 2. Cartel promocional de la exposición Aspectes de la fotografía al País Valencià. 1980.

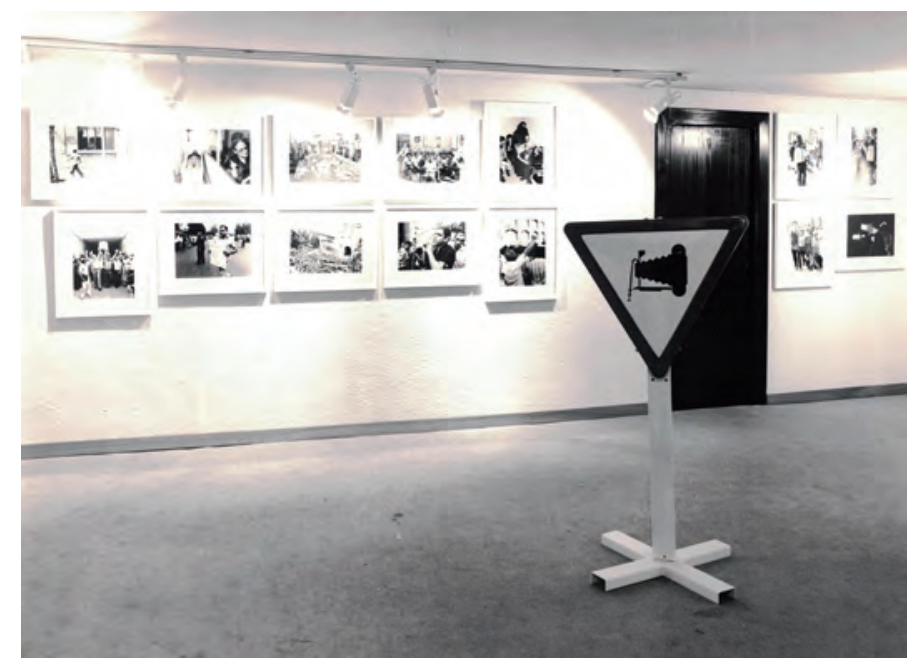

Fig. 3. Imagen de la exposición Aspectes de la fotografía al País Valencià. 1980. Archivo de Artur Heras.

de la gestión de la Sala Parpalló durante estos años fue la apertura de fronteras al colaborar con otras instituciones, públicas y privadas, dentro y fuera del país. De hecho, la de Walker Evans fue una exposición producida por el State of Walker Evans que, posteriormente, gracias a los contactos de la Sala Parpalló y a convertirse en un referente a nivel nacional, viajó a Madrid, a Barcelona y a Fiesole.

Otra de las exposiciones que mayor repercusión tuvo fue la retrospectiva de Robert Frank (19242019) -Robert Frank. Fotografías/films 1948/1984 (1985)-, la primera que se hacía en España, pero que tenía como precedentes algunas muestras celebradas en ciudades como Montreal, Los Ángeles o Zúrich. Sobre la cuestión del estilo de Robert Frank se han escrito muchas páginas, pero el punto de vista de esta muestra indagaba más en el concepto de imagen. Integrada por varias series como The Americans y otros trabajos más experimentales, sirvió como inspiración y puente para incorporase a una exposición mayor que su amigo Robert Delpire organizó en el Centre National de la Photographie de París poco después.

Cabe recordar que ese mismo año se celebra, con motivo de las II Jornades Fotogràfiques a València, una muestra sobre August Sander (1876-1964) en la Sala Parpalló (1985), inaugurada de manera simultánea a otras en espacios distintos como la de John Gutmann 1934-1939 en la galería Visor. La inclusión de Sander en estas jornadas fue todo un acierto, ya que su obra en España solo había sido expuesta con anterioridad en Tarragona. Recientemente hemos asistido a la recuperación de la obra de este fotógrafo, estando su obra expuesta en La Virreina. Centre de la Imatge de Barcelona, promocionándose como la mayor retrospectiva que sobre el autor se ha llevado a cabo en el estado español. A pesar de ser cierto, apenas se hace mención de la idea pionera que se llevó a cabo mucho antes en la Sala Parpalló.

El compromiso social y político de la gestión de la Sala Parpalló que traslució desde sus inicios, cobró forma con la puesta en valor, en 1987, de parte del legado del que posiblemente sea el fotógrafo más conocido de la Guerra Civil española, Robert Capa (1913-1954). La exposición Robert Capa. Cuadernos de guerra en España (1936-1939) sirvió para atraer a un público variado y aproximarse a un legado que iba más allá del valor estético de la fotografía, esto es, el valor como documento sociocultural.

Ese mismo año, otra muestra señala a la Parpalló como emblema de contemporaneidad y aperturismo, Lisette Model. Restrospectiva 1937-1970 (1987). La fotógrafa (1901-1983), austriaca de nacimiento, cultivó un estilo personal tanto en sus instantáneas personales como las disparadas por encargo, que la 
alzaron a lo más alto del panorama artístico internacional. De hecho, en 2009, la Fundación Mapfre en colaboración con el Jeu de Paume de París organizó otra retrospectiva que algunos medios apuntaban como la primera en España desde 1998, obviando totalmente la expuesta en la Parpalló once años antes. ${ }^{11}$

En esa misma línea relativamente pionera y moderna, se encuentra el traer a Valencia la obra de un autor polémico como es Joel-Peter Witkin (1939), en colaboración con el Centro de Arte Reina Sofía (1988-1989). Era la primera vez que parte de la producción de este artista podía disfrutarse en la ciudad, siendo una de sus primeras exhibiciones en solitario a nivel internacional que contribuyó a afianzar su fama. ${ }^{12}$

La cooperación de la Parpalló con otros centros, como mencionábamos anteriormente, fue constante. Otra exposición que venía organizada por el Museo Carnavalet de París fue la de Cartier Bresson en 1990, titulada Paris à vue d'œil. Cartier-Bresson fue un valor en alza tanto dentro de la esfera mercantil fotográfica como en relación a los aspectos estéticos en boga en torno a los años 90, justo en el momento en el que se organizó la muestra. Por tanto, la gestión y propuestas de la Sala Parpalló siempre estuvieron ligada a las tendencias internacionales del momento.

Pero no solo los fotógrafos más conocidos, mediáticos y valorados por la crítica global ocuparon la programación de la sala ese año. El también fotógrafo francés Jean Dieuzaide (1921-2003) expondría parte de su trayectoria de carácter documental y etnográfico en la Parpalló (1990), una mirada extranjera a parte del pueblo español, que hace apenas unos años recibió de nuevo una muestra más extensa en el Museu Valencià d'Etnologia en su recorrido por este país que tanto le fascinaba.

El talante más arriesgado de la programación de la sala quizá se lo debemos a la exhibición -en algunos casos por primera vez en España- de cineastas que desarrollaron también una labor fotográfica muy intensa: Dennis Hopper (1936-2010), David Lynch (1946) y Wim Wenders (1945). La exposición de David Lynch (1992) contó con un presupuesto algo más decente comparado con la anterior muestra de Hopper (1991), y sirvió para exhibir por primera vez en España parte de su obra

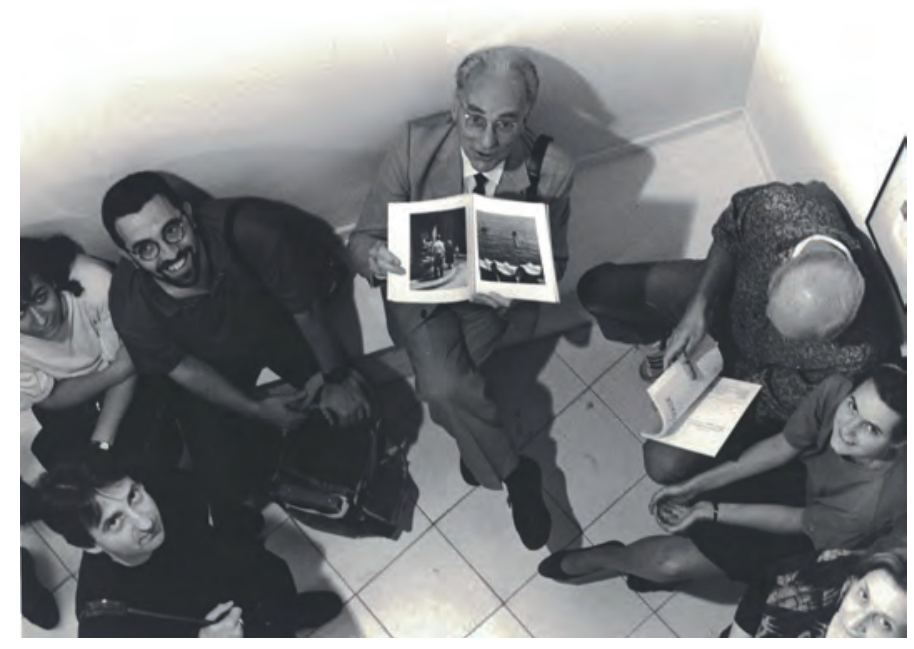

Fig. 4. José García Poveda 'El Flaco'. Jean Dieuzaide mostrando a cámara el catálogo, resultado de su exposición, conformando el número 15 de la Colección Imagen. 1990. Archivo de Artur Heras.

artística más allá del cine y la televisión. Un ciclo fílmico sobre Lynch organizado desde la Filmoteca de Valencia sirvió de excusa para que Heras viajase a Los Ángeles a conocer al cineasta y organizase una muestra doble de su obra visual: mientras que en la Sala Parpalló se expuso su obra de talante más pictórico, el Palau dels Scala estuvo ocupado por sus fotografías. Las muestras de este artista a nivel nacional traspasaron el interés artístico para tener un alcance cultural y social, sobre todo porque el mismo artista accedió a acudir a la inauguración. ${ }^{13}$ Por su parte, la exhibición de Wim Wenders (1994), volvió a repetir el hito, convirtiéndose en una de las primeras exposiciones suyas en territorio español. ${ }^{14}$

Para finalizar este apartado, remarcando el afán vanguardista y arriesgado de Artur Heras como gestor y programador de la sala durante los años que desempeñó dicha labor, mencionaremos la antología dedicada al fotógrafo Duane Michals. Fotografías 1958-1990 (1932), por primera vez expuesto en solitario en España (1993). Siguiendo la estela de ausencias referenciales a la Sala Parpalló como pionera en el ámbito expositivo, en el año 2002 la Galería Max Estrella anunciaba que era la

\footnotetext{
11 ZELICH, Cristina (com.), 2009; MASDEARTE.COM, 2009.

12 NAVAS FERNÁNDEZ, Alexis, 2009-2010, p. 502.

13 CERVERA, Rafa, 2017.

14 FALCES, Manuel, 2002.
} 


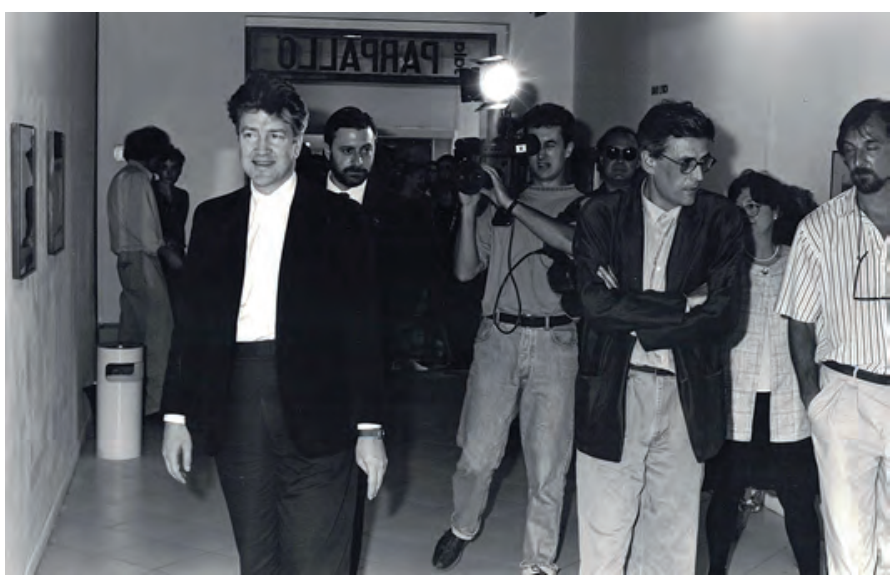

Fig. 5. José García Poveda 'El Flaco'. David Lynch entrando a la Sala Parpalló junto a Artur Heras. 1992. Archivo de Artur Heras.

primera vez que una galería privada española contaba con obras del fotógrafo, y también en 2017 la fundación Mapfre Barcelona organizaba una retrospectiva en torno a su figura sin mencionar el citado espacio. ${ }^{15}$

\section{España: fotografía y vacío(s)}

Aunque analizar la consideración artística de la fotografía no es el contenido del presente texto, la tradición historiográfica sobre la fotografía en España -al igual que en todos los lugares donde se desarrolló el invento- ha reservado una parcela importante a la lucha encarnizada por el reconocimiento de la misma como medio artístico y expresivo. A este respecto, el fotógrafo Xavier Miserachs (1937-1998) desarrolla en su obra teórica sugestivas ideas sobre los intereses de quienes escriben la(s) Historia(s) de la fotografía y las premisas en su concepción, especialmente durante las dos últimas décadas del siglo $X X .^{16}$
Tal como se ha apuntado en líneas anteriores, la tradición historiográfica sobre la fotografía en el ámbito nacional ha considerado la década de los 70 como los años que inician la fotografía de autor tal y como se concibe hoy en día. Sin embargo, a pesar de escasear el aparato bibliográfico, no hay que olvidar que generaciones anteriores ya habían intentado romper con el salonismo, apostando por la profesionalización del medio más allá de su presencia en ritos de paso como bodas, bautizos, comuniones y defunciones. ${ }^{17}$ Esta ausencia en la historiografía puede deberse, en parte, al "vacío expositivo y mercantil que para el caso de España podemos ampliar a su etiología a las específicas circunstancias culturales y socio-políticas del franquismo". ${ }^{18}$

Sea como fuere, la historiografía nacional ha instruido que los años 70 son el punto de partida para considerar el estatuto artístico de la fotografía, justificándose a través de la regularidad de las muestras expositivas, el auge del coleccionismo y la incursión en colecciones museísticas o la regularización de la actividad profesional, entre otras razones. Sin embargo, sería injusto dejar de mencionar la labor que desde principio del siglo XX algunas agrupaciones o sociedades fotográficas españolas junto con otras tantas publicaciones sobre la materia habían llevado a cabo, abonando el terreno a las instituciones, organizaciones o conglomerados expositivo-divulgativos en territorio nacional. De hecho, como recoge Carmelo Vega, el primer proyecto expositivo sobre fotografía en España data de 1864, iniciativa de la revista madrileña El Propagador de la Fotografía. Y ya pasadas las primeras décadas del siglo $\mathrm{XX}$, existe una preocupación por dar a conocer el trabajo de fotógrafos españoles en distintos lugares de la geografía o fuera de ella organizando los denominados "salones circulantes" en diferentes provincias de España y promoviendo las muestras monográficas de fotógrafos foráneos en los Salones de Arte Fotográfico Extranjero, lo que permitía por

\footnotetext{
15 GALERÍA MAX ESTRELLA, 2001.

${ }^{16}$ MISERACHS, Xavier, 1997; MISERACHS, Xavier, 1998.
}

17 En relación a los cambios acontecidos en torno a la década de los 60 en materia expositiva sobre fotografía, destacan dos muestras, hoy consideradas clásicas, que recogían fotografías de Ricard Terré (1928-2009), Xavier Miserachs (1937-1998) y Ramón Masats (1931), la primera celebrada en 1957 y expuesta en lugares referenciales de la vanguardia fotográfica: la Agrupación Fotográfica de Cataluña en Barcelona, la sede de AFAL en Almería y la Real Sociedad Fotográfica de Madrid. Dos años después, en 1959, se recuperó la misma tríada cuyas obras fueron presentadas, en este caso, en la Sala Aixelà de Barcelona. MACBA, s/f. En paralelo, durante estos años se refuerza la vinculación teórica con el medio de la mano de figuras como Oriol Maspons (1928-2013), quien publicó asiduamente textos sobre fotografía en revistas como Arte fotográfico o AFAL. Además, colecciones como Palabra e Imagen (1961-1985) apuntaban la colaboración entre escritores y fotógrafos, poniendo voz y vista a las nuevas intenciones del medio.

18 MIRA, Enric, 1990, p. 100. 
un lado la difusión y expansión de la fotografía nacional, y por otro el intercambio de ideas con la fotografía vecina. ${ }^{19}$

Coincidiendo con la máxima historiográfica, fue el 18 de octubre de 1973 cuando se inaugura la galería Spectrum en Barcelona, fundada por Albert Guspi y Sandra Solsona. Aunque fue a partir de 1977 cuando incorporó en su programación los nombres de grandes clásicos modernos de la fotografía, durante los años anteriores ya se consolidó como referente al convertirse en la primera galería española dedicada en exclusivo a la fotografía y que aunaba en su intención expositiva la incorporación de fotógrafos internacionales de renombre y la presentación de autores locales que empezaban a despuntar. ${ }^{20}$

Alrededor de 1980 ya se cuenta con más de diez galerías fotográficas en España, aunque su volumen económico era escaso. En realidad, como apunta Enric Mira, la actividad de las galerías fotográficas en territorio nacional no se puede medir por su rentabilidad, sino más bien como catalizador de inquietudes. ${ }^{21}$ El mismo Guspi, que había vislumbrado el auge del mercado fotográfico en Estados Unidos y Europa, y que generó iniciativas para impulsar el mismo afán en su país, alertaba de la necesidad de la incursión de la imagen fotográfica en los museos y en la enseñanza universitaria. ${ }^{22}$

La visibilización de la fotografía como medio creativo también fue auspiciada en esos años por otras propuestas que provenían de distintos frentes. Uno de ellos es el de las muestras fotográficas que, aunque aisladas, contribuyeron a la inclusión del medio fotográfico en espacios expositivos con un relativo calado social. Cabe recordar que, por ejemplo, en el año 1982, se llevaron a cabo muestras sobre instantáneas contemporáneas como Fotografía Iberoamericana en el Museo Español de Arte Contemporáneo de Madrid, Cinc Mestres de la Fotografia Catalana, presentada en el marco de la Primavera Fotogràfica en Barcelona, ${ }^{23}$ o la exposi- ción monográfica sobre Nicolás de Lekuona. Obra fotográfica en el Museo de Bellas Artes de Bilbao. ${ }^{24}$ Además, otros museos relevantes, como el Museo Nacional Centro de Arte Reina Sofía, acogieron poco a poco muestras fotográficas pioneras en esta época, con todo lo que ello suponía ${ }^{25}-$ la adquisición de este tipo de material y, como consecuencia, que dichos museos acabaran incorporando departamentos de conservación fotográfica con personal especializado en gestión, conservación y almacenaje de fondos de esta naturaleza-. ${ }^{26}$

Parte del rastro que dejaron estas exposiciones puede apreciarse gracias a las publicaciones que nacieron ligadas a las mismas. En suma, retroalimentando estos hechos, encontramos publicaciones especializadas como la revista Nueva Lente (1971-1983) que aglutinó -al igual que años antes haría la revista AFAL (1956-1963)- a un nutrido grupo de fotógrafos y teóricos interesados en la labor fotográfica, marcando la tendencia estética.

Por otro lado, fueron múltiples los movimientos de carácter más o menos efímero y de programación desigual que poblaron algunos grandes núcleos urbanos. Su labor se centraba en la difusión y en el intercambio vital en detrimento del valor comercial. Europa ya había asistido, en 1979, a un festival de fotografía celebrado en el marco de la Bienal de Venecia durante ese mismo año. $Y$, poco después, en 1980 se inició la tradición del Mois de la Photo en París. ${ }^{27}$ No obstante, en España fue necesario esperar hasta el final de la dictadura para ver cómo, tímidamente, el arte fotográfico empezaba a cobrar fuerza en espacios públicos. Como consecuencia, nace entonces uno de los principales festivales de fotografía por su influencia y duración, la Primavera Fotogràfica de Barcelona. Al mismo tiempo, Madrid acoge otro festival con la misma intención, pero mucho más efímero, FocoFotografía. Todos ellos tenían algunos precedentes tempranos como la iniciativa surgida de la Societat Fotogràfica de Lleida de la mano de su pre-

19 VEGA, Carmelo, 2017, p. 277 y 305.

20 RIBALTA, Jorge; ZELICH, Cristina, 2012, p. 284; ZELICH, Cristina, 2018, p. 28.

21 MIRA, Enric, 1991, p. 23.

22 ZELICH, Cristina, 2018, p. 33.

23 La Primavera Fotogràfica es un festival bianual creado en 1982, que comprende distintas exhibiciones y actividades en materia de fotografía, y actualmente promovido por el Centre d'Art Santa Mònica.

24 GARCÍA, Manuel, 1984, s/p. Otras exposiciones colectivas relevantes sobre fotografía las recoge José Ramón Cancer Matinero, quien destaca especialmente Historia de la fotografía española contemporánea (1950-1986), celebrada en Sevilla en 1986. CANCER MATINERO, José Ramón, 2013 p. 109.

25 ALBARRÁN DIEGO, Juan, 2012, p. 224-230.

26 CORONADO E HIJÓN, Diego, 2000, p. 56.

27 FONT DE MORA, Juan Pedro (coor.), 2005. 
sidente, Toni Prim, responsable durante cinco años del certamen Fotomostra Iltirda, que sería el germen de la Fotomostra de Lleida, celebrada por primera vez en $1979 .{ }^{28}$ A partir de entonces, certámenes, festivales y exposiciones dedicadas en su totalidad a la fotografía empiezan a crecer en número, apareciendo varias ediciones de eventos tan destacables como las Semanas Fotográficas de Guadalajara.

Olivier Richon, partiendo de las ideas planteadas por Jacques Rancière en La división de lo sensible. Estética y política, ejemplifica la sospecha de la crítica sobre las artes mecánicas y reivindica que estas deben, primero de todo, ser "experimentadas y reconocidas como arte, no simplemente como técnicas de reproducción y difusión". ${ }^{29}$ Esta afirmación nos permite llegar a entender, entonces, la deriva fotográfica y su tratamiento por parte de los especialistas en el medio a partir de la segunda mitad del siglo pasado. En líneas generales, la vuelta a la figuración en el campo de las artes puede explicar que la fotografía, al estar inscrita entre los extremos del conceptualismo y la figuración, empiece a cobrar importancia como referente estético, augurando que pronto lograría ocupar un lugar propio.

A pesar de su naturaleza ambivalente y de los vacíos intencionados que en su historia se han ido construyendo, el medio fotográfico por fin empezaba a posicionarse en el punto justo entre la obra artística y el documento social. Con todo ello, parece que desde los años 80 del siglo XX nadie duda del valor creativo y documental de la fotografía. La creación de un mercado propio sobre fotografía también contó, entre sus consecuencias, con la llamada de atención hacia los agentes del ámbito museal, quienes empezaron a plantearse la necesidad de nuevos espacios expositivos concretos referidos al medio.

Progresivamente, en territorio nacional la fotografía ingresa en instituciones tanto privadas como públicas. Algunas galerías que hasta este momento eran ajenas a este medio artístico empiezan a res- paldar la adquisición de piezas fotográficas, al tiempo que comienzan a ser expuesta con regularidad en ferias de arte contemporáneo, lo que posibilita e incita que aparezcan otro tipo de coleccionista, y la fotografía comienza, entonces, a convivir con otras manifestaciones artísticas sin pudor.

\section{Valencia mira a la fotografía}

A grandes rasgos, los acontecimientos políticos que iban sucediendo en el territorio español marcaron las pautas culturales que rigieron el horizonte cultural en las últimas décadas del siglo XX. Los años 80 , con su afán aperturista, fueron testigo de la aparición de alternativas culturales que apostaban por la descentralización de la cultura, tanto desde el ámbito público como desde esferas privadas. Durante el período inicial de la Transición se gestaron herramientas jurídicas clave para lograr alcanzar el propósito de diversificación y dinamización de la cultura. En este contexto, se entiende la creciente aparición de museos, galerías y salas de exposición, dedicadas fundamentalmente al arte contemporáneo. ${ }^{30}$ Sin embargo, en los años 90 , ya instaurada la democracia y tras el boom económico, las reducciones financieras dejaron su huella, especialmente en el campo de las galerías. ${ }^{31}$

El panorama cultural valenciano antes de los años 80 estuvo subyugado al inmovilismo, a pesar del deseo de modernidad de ciertos proyectos alentados por galerías privadas. Sin embargo, a partir de entonces la actividad artística en Valencia estuvo marcada por hechos importantes que hicieron de la misma una de las más dinámicas culturalmente hablando. Entre otros factores, es en este momento cuando los artistas valencianos de varias generaciones empezaban a ser considerados en el panorama nacional, llegando a ocupar puestos relevantes, auge que sirvió para que sus obras se incluyesen en las listas de deseos de los coleccionistas. En cuanto a los artistas emergentes, la Facultad de Bellas Artes de Valencia había aumentado su número de estudiantes considerablemente en relación a la década anterior. ${ }^{32}$ Las galerías priva-

\footnotetext{
${ }^{28}$ ZELICH, Cristina, 2018, p. 45.

29 RICHON, Olivier, 2007, p. 79.
}

30 Rescatando diversas investigaciones de Román de la Calle, pueden citarse como ejemplos importantes la apertura del Museo Nacional Centro de Arte Reina Sofía (1986), de Arteleku. Centro de Arte de San Sebastián (1987), el Centro Atlántico de Arte Moderno en Las Palmas de Gran Canaria (1989) o la creación de la Fundació Tàpies (1990). Además, no podemos olvidar que en 1982 se inaugura la tradicional Feria Internacional de Arte Contemporáneo de Madrid, ARCO. En el contexto valenciano, en 1970 se abría el Museu Popular d'Art Contemporani de Vilafamés y diez años más tarde, en 1980, el Museu d'Art Contemporani d'Elx gracias a la iniciativa de un grupo de artistas. DE LA CALLE, Román, 2005, p. 20; DE LA CALLE, Román, 2006, p. 185.

31 SILVESTRE GARCíA, Laura, 2012, p. 44.

32 Es necesario tener en cuenta que fue en este contexto cuando la Escuela de Bellas Artes de San Carlos se convirtió en facultad, adscribiéndose a la Universitat Politècnica de València. DE LA CALLE, Román, 2006, p. 188. 
das existentes desde los años 60 se habían consolidado y ganado prestigio, $^{33}$ y muchas nuevas se abrieron en la ciudad para promocionar el arte actual. ${ }^{34}$ Sin embargo, lo que caracterizó el ambiente valenciano en el campo de las artes fue el deseo intrínseco por configurar un museo de arte moderno que actuase como alternativa a las galerías y que situase a Valencia en el mapa internacional artístico.

Hasta entonces, el arte contemporáneo -y por extensión el fotográfico- se había asomado a la ciudad de Valencia a través de dos plataformas fundamentalmente. Por un lado, respecto a la esfera pública, en los 80 ya se habían expuesto en la ciudad obras actuales en las salas del Ajuntament de València destinadas a usos expositivos, manteniendo una programación regular acorde a los gustos estéticos que se iban adaptando a los tiempos. Por otro, vinculado al ámbito privado, cabe señalar las salas pertenecientes a fundaciones o entidades bancarias, como el Centre Cultural Bancaixa (1982), el Centro Expositivo de Ibercaja en Valencia (1983) y, más tardíamente, el Aula Cultural CAM La Llotgeta (1994). ${ }^{35}$

La consolidación de estos hechos hace entrever que, especialmente durante la década de los 80 en España en general, y en Valencia en particular por la demora del ansiado museo de arte moderno, se tenían unas expectativas esperanzadoras para acabar con la descentralización de la cultura. La inauguración del Institut Valencià d'Art Modern en 1989 -aunque estaba gestado años antes, desde 1986- supuso, como ya hemos dicho, un paso importante hacia dicho objetivo, asumiendo como funciones propias el "fomento y difusión del arte moderno", así como la constitución, custodia, organización y exposición de "colecciones museísticas representativas del arte moderno". ${ }^{36}$

Ante esta declaración inicial, no es de extrañar que el IVAM, como referente, incorporara paulati- namente en sus fondos y muestras la fotografía, abrazando al medio que revolucionó las artes. Junto a los clásicos europeos y norteamericanos, la colección del museo cuenta con lo más sobresaliente de la vanguardia fotográfica nacional y con los archivos de fondos antiguos como los cedidos por la Real Academia de Bellas Artes de San Carlos, la obra de Gabriel Cualladó, la colección de los hermanos Mayo, el depósito donado por la familia Ordóñez/Falcón y los premios Hoffmann de fotografía que recogen lo más destacado de la última generación de fotógrafos jóvenes españoles. ${ }^{37}$

Sin embargo, quedarse únicamente con la relevancia y consolidación del IVAM es insuficiente teniendo en cuenta las ansias de emergencia cultural que caracterizaron las mentalidades de ese tiempo. Al iniciarse la década de los 80 , sin existir todavía el IVAM, irrumpían en escena espacios como la Sala Parpalló o plataformas que partían de lo privado y que han subsistido hasta hace poco de manera independiente como la galería Visor (1982) o la fotogalería Railowsky (1985), ejerciendo de trampolín para el impulso de la fotografía en Valencia. ${ }^{38}$ Anteriormente, la actividad fotográfica en Valencia se había desarrollado en torno a asociaciones de carácter altruista como el Foto Club y la Agrupación Fotográfica de Valencia. ${ }^{39}$

Como se ha adelantado, en el año 1982 se funda Visor bajo el impulso de Josep Vicent Monzó y Pep Benlloch, un espacio cuya filosofía expositiva desde el principio se ha centrado "en la combinación de artistas jóvenes que trabajan en el ámbito de la fotografía, junto con fotógrafos de contrastada reputación internacional".40 De hecho, si tenemos en cuenta la fecha de inicio y la máxima citada, se observa cómo en el mismo año de apertura se traen a Valencia exposiciones como la antológica de más de 150 imágenes que Gabriel Cualladó (1925-2003) expuso en la Primavera Fotogràfica de ese año en Barcelona. Lamentablemente, recién hemos asisti-

33 El investigador Román de la Calle apunta que, al inicio de la Transición política, funcionaban en Valencia una media docena de galerías de arte. DE LA CALLE, Román, 2006, p. 182.

34 HERAS, Artur, 1991, p. 4-5.

35 DE LA CALLE, Román, 2006, p. 188; SILVESTRE GARCÍA, Laura, 2012, p. 42. Además, también se ha destacado la labor de algunas sedes expositivas ligadas a entidades bancarias en pueblos cercanos a Valencia, como la Sede Cultural de la Caja Rural de Torrent o el Centro Cultural de Caixa-Carlet. DE LA CALLE, Román, 2005, p. 22.

36 Comunidad Valenciana. Ley 9/1986, de 30 de diciembre, por la que se crean los Entes de Derecho Público "Instituto Valenciano de Artes Escénicas, Cinematografía y Música" "Instituto Valenciano de Arte Moderno". Diari Oficial de la Generalitat Valenciana, 07-01-1987, $\mathrm{n}^{\circ} 500$

37 CORONADO E HIJÓN, 2000, p. 56; CANCER MATINERO, 2013, p. 103

38 FONT DE MORA, Juan Pedro (coor.), 2005, p. 7-10.

39 MIRA, Enric, 1990, p. 101.

40 ESPAIVISOR, s/f. 


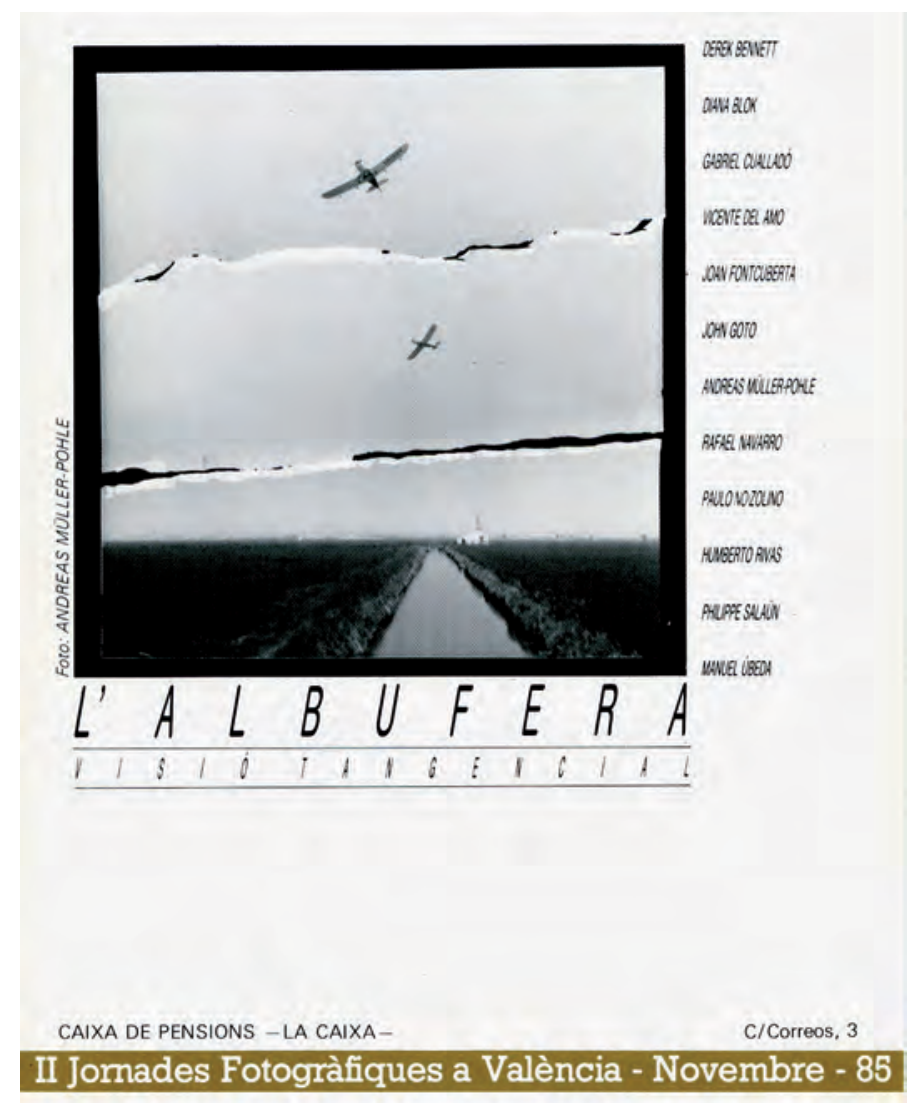

Fig. 6. Panfleto promocional de la exposición L'Albufera. Visió tangencial, celebrada en el marco de las II Jornades Fotogràfiques a València. 1985. Archivo de Francesc Vera.

do a la desaparición de Visor en dicha ciudad, trasladándose el proyecto a Madrid, y dejando a Valencia sin una galería especializada en fotografía.

Tres años más tarde, en 1985, tomando el nombre de la famosa instantánea de Cartier-Bresson, se funda la fotogalería Railowsky de la mano de los hermanos Font de Mora, que aunaba a la perfección el resuello fotográfico esperado en esta ciudad. Por un lado, este espacio estuvo destinado inicialmente a servir como librería especializada en publicaciones seleccionadas en torno a los estudios de la imagen y la comercialización de fotolibros destacados del momento tanto del ámbito nacional como internacional. Por otro, actuó también como sala expositiva donde dar a conocer a fotógrafos emergentes $y$, con el tiempo, a algunas celebridades antes ausentes en el circuito expositivo valenciano, entre los que se encontraban nombres como Carlos Cánovas (1951) o Chema Madoz (1958). De ese modo, el espacio cubría un doble vacío en la ciudad, el formativo y el de exhibición, pero más allá de esta doble parcela, sirvió como espacio de reunión y debate de los amantes de lo fotográfico fuera de las asociaciones o sociedades fotográficas, que en algunos casos habían quedado un tanto obsoletas en cuanto a planteamientos aperturistas. Desde el inicio, programaron eventos que ponían de manifiesto el ansia por conocer y cuestionar el medio de masas y adentrarse en sus múltiples facetas. Como ellos mismos definen, su modus operandi es hacer mucho con pocos recursos, uniendo el mundo de la fotografía con el del libro -anticipando la pasión desmesurada por el foto-libro como objeto-. En esta trayectoria de más de treinta años, han realizado un gran número de muestras individuales y colectivas, presentaciones de libros, mesas redondas, soporte a iniciativas autoeditadas, y todo tipo de propuestas culturales en torno a la imagen.

Simultáneamente a la apertura de estos espacios, en la ciudad de Valencia se estaban gestando iniciativas en torno a la fotografía respaldadas por instituciones como la Generalitat Valenciana o las mismas galerías privadas. Es el caso de las I Jornades Fotogràfiques a València celebradas en el año 1984 siguiendo el patrón de las ya mencionadas Semanas Fotográficas de Guadalajara o la Primavera Fotogràfica de Barcelona. ${ }^{41}$ En palabras de dos de los organizadores de este primer encuentro fotográfico de la ciudad, "València no pot ni deu viure d'esquena al moviment d'apropament a la imatge fotogràfica que s'està produint en l'actualitat", añadiendo que "constitueix el vehicle que en major mida és capaç de transmetre ingredients estètics a la comunitat". ${ }^{42}$ En cuanto a los objetivos de este círculo, destacó el interés por la difusión y normalización de las fronteras trazadas en el imaginario fotográfico, así como insertar la fotografía valenciana dentro de un panorama cultural más amplio, mostrando al público las imágenes que se estaban capturando en otros lugares de España. De hecho, esta primera edición estuvo protagonizada por una serie de exposiciones de talante autonómico que reflejaba las distintas partes de España.

Un año después, en 1985, se celebró la segunda edición de estas Jornades Fotogràfiques a València,

41 CANCER MATINERO, José Ramón, 2013, p. 105.

42 BENLLOCH, Pep; VICENT MONZÓ, Josep (coors.), 1984, s/p. 
de las que se esperaba algo similar a las primeras. Sin embargo, la fórmula por la que se optó fue distinta y lo que marcó el evento fue la contradicción o la confusión entre el ansia aperturista y la carga de provincianismo. Con todo, se decidió dedicar estas segundas jornadas a la fotografía del período de entreguerras y al retrato, y para complementar dicho propósito se puso en marcha un proyecto expositivo que comprendía muestras celebradas de forma simultánea en la ciudad. Quizá, la más destacable fue L'Albufera. Visió tangencial, que reunía la obra de cinco fotógrafos españoles y otros cinco de fuera que habían trabajado previamente este tema, centrándose, coincidentemente, en los alrededores de este espacio natural, y no en el lago propiamente dicho, de ahí el título por el que se optó para bautizar la exposición.

Como se puede comprobar, los años que comprenden los 80 prestaron a la ciudad de Valencia iniciativas interesantes en cuanto a lo fotográfico que dieron paso al crecimiento y valoración del medio a un nivel más general. A parte de la actividad fotográfica desarrollada intramuros, no podemos finalizar sin apuntar brevemente algunas muestras que tuvieron trascendencia internacional lejos de Valencia, como Spanische fotografie aus Wien, una exposición de fotógrafos valencianos celebrada en 1986 en la Fotogalerie Wien de Viena entre la que se encontraba obra de Eduard Ibáñez, Francesc Vera, Josep Vicent Monzó, Manuel Rodríguez y Emilio Maldonado; la inclusión de una exposición de fotografía valenciana en el pabellón de esta comunidad autónoma en la Exposición Universal de Sevilla de 1992; y la muestra sobre fotógrafos valencianos en la Exposición Internacional de Ise en 1995, que contó con 25 participantes. ${ }^{43}$

Es aquí donde toma posición la Sala Parpalló, uno de los primeros espacios que supuso una alternativa al feudo artístico en esos momentos en Valencia. Su papel fue, como se ha visto, el de mostrar, en forma de exposiciones temporales, arte contemporáneo que por sus características o contenidos no había podido ser expuesto con anterioridad en España, incluyendo la fotografía, así como arte emergente por parte de artistas nacidos o formados en dicha ciudad. Evidentemente, la apertura de nuevos espacios progresivamente tras la inauguración de la Sala Parpalló cambió el devenir de la misma, hasta quedar en una nomenclatura que, en la actualidad, en un acto de deferencia, ven reposar las paredes del MuVIM.

Para ser justas, también a finales de esa década el ambiente artístico español dio un vuelco favorable hacia lo fotográfico. La Ley 16/1985, de 25 de junio, del Patrimonio Histórico Español contempla la fotografía en el "Capítulo I. Del Patrimonio Documental y Bibliográfico". ${ }^{44}$ Esta nueva tendencia propició un ambiente óptimo para que en distintos lugares de España se empezara a pensar la fotografía desde los espacios museísticos, fundamentalmente a partir de la segunda mitad de la década de los 80. Un ejemplo de ello es la muestra organizada en la Biblioteca Nacional de España en 1989 para conmemorar el 150 aniversario del medio. Los museos más destacados de las ciudades comenzaron, entonces, a incorporar departamentos de conservación y gestión del patrimonio fotográfico. En suma, la sensibilidad hacia el conocido como medio de masas empezó a cambiar paulatinamente, aunque como en cualquier proceso de desarrollo, existen luces y sombras.

Por otro lado, fue en los años 90 del siglo XX cuando la teoría fotográfica empieza a afianzarse. Con el respaldo de la parcela teórica en plena efervescencia, así como con las novedades en cuanto al valor de lo fotográfico a nivel material, en Valencia, como en otros lugares de territorio nacional, se produce una eclosión de atención al medio. Además de la mencionada labor del IVAM en cuanto a políticas adquisitivas y la creación del departamento de conservación, surgieron en la ciudad nuevos ejemplos de adquisiciones de fondos fotográficos tanto de ámbito público como privado insertas en colecciones de arte contemporáneo.

Desde 1991, a modo de ejemplo, podemos citar la compra de fotografías por parte del Patronato Martínez Guerricabeitia con motivo de la celebración de sus bienales. También la Biblioteca Valenciana, creada por decreto en 1985, y con sede propia en el antiguo monasterio de San Miguel de los Reyes desde el año 2000, constituye sin duda un paradigma de este espíritu por conservar la memoria por medio de los documentos fotográficos, albergando y adquiriendo colecciones y fondos como el de José Huguet, el archivo de Francesc Jarque en 1999, y posteriormente los archivos Desfilis y Finezas, entre otros. Actualmente, la colección de la Biblioteca Valenciana cuenta con 471 mil fotografías,

43 Llegadas a este punto, queremos agradecer el testimonio del fotógrafo Francesc Vera, quien gracias a su experiencia y dedicación a la fotografía del contexto valenciano nos ha iluminado en muchos aspectos del presente texto, apenas tratados desde el punto de vista de la historia del arte.

44 MURO BORRÁS, Bárbara, 2016, p. 271 
de las cuales más de 70 mil están digitalizadas. ${ }^{45} \mathrm{~A}$ esto podemos añadir las colecciones de otros archivos, museos o sedes de la Diputación e instituciones públicas en donde la fotografía ocupa un lugar destacado. Al mismo tiempo, iniciativas privadas avalaron el medio desde temprano: el afán por custodiar fotografía cuenta en su haber con renombrados coleccionistas, entre ellos el ya mencionado José Huguet, Juan José Díaz Prosper o Rafael Solaz.

\section{Más allá de lo exhibido. A modo de conclusión}

Recopilando. Por lo que respecta al ámbito nacional, la valoración definitiva del medio se inició en la década de los 60, aunque la historiografía, tradicionalmente, ha datado el punto álgido en los años posteriores. En este campo, el grueso expositivo recayó en iniciativas privadas, hasta que finalmente, en los años 80, después de superar el hermetismo de los años de dictadura, el ambiente cultural dio un vuelco favorable hacia lo fotográfico. A pesar de ello, en la actualidad, salvo pequeños proyectos autonómicos, no existe en España ningún espacio expositivo público dedicado exclusivamente a la fotografía.

La Sala Parpalló supuso un empuje definitivo para la introducción sin complejos de la fotografía en Valencia. Cuando se le pregunta a su gestor y programador, Artur Heras, por la razón de darle tanta relevancia a lo fotográfico dentro del itinerario artístico del espacio, contesta con cierto sarcasmo que desplazar fotografías era más rápido y barato. ${ }^{46}$ La precaria situación que precedía a la fotografía, su gestión, conservación y difusión como artefacto cultural, así como la ausencia de leyes claras sobre cómo proceder, benefició, allá por los años 80 , el movimiento y comisariado de tales acontecimientos museográficos.

Las propuestas expositivas de este espacio, a través de la selección de obras de varios fotógrafos y fotógrafas, da una idea clara de las políticas culturales que guiaron la Sala Parpalló, que contribuyó a reforzar un canon clásico de la fotografía, incidiendo en aquella de carácter documental. A partir de aquí, quedaba mucho por hacer. A día de hoy, dentro del panorama valenciano, nuevos organismos artísticos como la Fundació per Amor a l'Art, con sede en Bombas Gens. Centre d'Art, se han su- mado a la compra y colocación de la fotografía en primera línea expositiva, centrando su discurso en torno a ella. Asimismo, en la era de la imagen, en donde la fotografía ocupa un puesto primordial, galerías de arte, salas como la Fundación La Posta -entidad sin ánimo de lucro-, y demás organismos de carácter cultural y artístico no pueden dejar de mirar lo fotográfico, convirtiéndose en un lugar común. En cuanto al panorama formativo y divulgativo, desde la Universitat Politècnica de Valencia se lleva a cabo el Máster en Fotografía, Arte y Técnica, que en 2017 organizó el I Congreso Internacional sobre Fotografía en la ciudad.

La Sala Parpalló recorre estos cambios generacionales desde los primeros años 80 hasta mitad de los 90. Las vicisitudes por las que gravita la fotografía a nivel nacional parecen tener un reflejo en esa senciIla propuesta que al inicio puede parecer localista. Como se ha visto en este escrito, algunos de los grandes nombres del arte y la fotografía internacional tuvieron hueco entre sus paredes y publicaciones -en algunos casos de forma pionera-, de manera discreta pero firme. Sin embargo, a pesar de lo que pudo suponer para una ciudad como Valencia albergar algunas de estas muestras, y el legado e impacto cultural que eso trajo consigo, la Sala Parpalló, a día de hoy, parece un espectro silencioso -o silenciado- por parte de la museografía.

\section{Bibliografía}

ALBARRÁN DIEGO, Juan. Del fotoconceptualismo al fototableau. Fotografía, performance y escenificación en España (1970-2000). Salamanca: Universidad de Salamanca, 2012.

BENLLOCH, Pep; VICENT MONZÓ, Josep (coors.). I Jornadas Fotogràfiques a València. Gener 1984. Valencia: Conselleria de Cultura, Educación y Ciencia de la Generalitat Valenciana, 1984.

CANCER MATINERO, José Ramón. "La fotografía en la Comunidad Valenciana en las últimas tres décadas". En: DE LA CALLE, R. (coor.). Los últimos 30 años del arte valenciano contemporáneo (II). Valencia: Real Academia de Bellas Artes de San Carlos, 2013, p. 88-113.

CERVERA, Rafa. "David Lynch: de Twin Peaks a València". Culturplaza, 14-05-2017 (en línea). En: <https:// valenciaplaza.com/david-lynch-de-twin-peaks-a-va lencia> (Fecha de consulta: 02-04-2019).

CORONADO E HIJÓN, Diego. "Origen y evolución histórica del patrimonio artístico fotográfico en los museos y los archivos estatales: el caso español en el final del segundo milenio", PH: Boletín del Instituto Andaluz del Patrimonio Histórico, 2000, 32, p. 50-60.

DE LA CALLE, Román. " 25 anys d'art a València. Els premis Alfons Roig i la història de la Sala Parpalló". En: DE LA

45 CANCER MATINERO, José Ramón, 2013, p. 102-103.

46 Testimonio del propio Artur Heras obtenido en la mesa redonda de las jornadas "La introducción de la fotografía en Valencia: la Sala Parpalló como caso de estudio", celebradas el 17 de octubre de 2018 en Espai d'Art Fotogràfic, Valencia, organizadas por las autoras del presente texto y con la participación de Artur Heras, Francesc Vera y Juan Pedro Font de Mora. 
CALLE, R.; BAUTISTA PEIRÓ, J. B. Sala Parpalló. 25 anys: 1 a parte, 14-XII-2005, 15-I-2006, $2^{\text {a }}$ parte, 25-I-2006, 26II-2006. Valencia: Diputación de Valencia, 2005, p. 9-59.

DE LA CALLE, Román. "25 años de arte en Valencia: los premios Alfons Roig y una aproximación a la historia de la Sala Parpalló (1981-2006)". En: El ojo y la memoria. Materiales para una historia del arte valenciano contemporáneo. Valencia: Universitat de València, 2006, p. 177-224.

FALCES, Manuel. "Viaje con cámara". El País, 06-07-2002 (en línea). En: <https://elpais.com/diario/2002/07/06/ba belia/1025910376_850215.html> (Fecha de consulta: 03-04-2019).

FONT DE MORA, Juan Pedro (coor.). La imagen inquieta. 20 años de la fotogalería Railowsky. (Exposición celebrada en Valencia, Col-legi Major Rector Peset de la Universitat de València y Fotogalería Railowsky, del 16-12-2005 al 19-02-2006). Valencia: Universitat de València, 2005.

GARCÍA, Manuel. "Jornadas sobre la fotografía". Cartelera Turia, 1984, 1042, s/p.

GARCÍA, Manuel. "Vida y muerte de la Sala Parpalló (1989-95). Notas sobre la difusión de la fotografía en Valencia". En: GAMÓN, M. (coor.). Artur Heras. Fundador de la Sala Parpalló. Valencia: Amics del Dia de la Foto, 1998, p. 7-11.

HERAS, Artur. 10 años de exposiciones de la Sala ParpaIló (1980-1990). Tesina de convalidación. Valencia: Universitat Politècnica de València, 1991.

LÓPEZ, José Alberto (dir.). "Sala Parpalló y Palau dels Scala". En: Lápiz. Revista Internacional de Arte, 1993, 11 (95-96), p. 122-123.

LUCAS, Pascual. "Entrevista con Artur Heras. Diez años en la Sala Parpalló". Cimal. Arte Internacional, 1990, 38 , p. 84-91.

MIRA, Enric. "Centre Fotogràfic Visor: El difícil encuadre de la exhibición fotográfica en Valencia". Cimal. Arte Internacional, 1990, 38, p. 100-103.

MIRA, Enric. La vanguardia fotográfica de los años setenta en España. Alicante: Instituto de Cultura Juan Gil-Albert, Diputación provincial de Alicante, 1991.

MISERACHS, Xavier. Fulls de contacte. Memòries. BarceIona: Edicions 62, 1997.

MISERACHS, Xavier. Criterio fotográfico. Notas para un curso de fotografía. Barcelona: Omega, 1998.

MURO BORRÁS, Bárbara. La obra fotográfica en el mercado del arte español. Tesis doctoral. Madrid: Universidad Complutense de Madrid, 2016.

NAVAS FERNÁNDEZ, Alexis. "Evolución y desarrollo del mercado del arte. El auge y consolidación de la fotografía en los mercados internacionales: El caso de Joel
Peter Witkin". Boletín de arte, 2009-2010, 30-3, p. 487510.

RAMÍREZ, Pablo. "Memoria de un premio". En: GAMÓN, M. (coor.). Artur Heras. Fundador de la Sala Parpalló. Valencia: Amics del Dia de la Foto, 1998, p. 13-14.

RAUSELL KÖSTER, Pau. Políticas y sectores culturales en la Comunidad Valenciana. Un ensayo sobre las tramas entre economía, cultura y poder. València: Tirant lo Blanch, Universitat de València, 1999.

RIBALTA, Jorge; ZELICH, Cristina. "De la galería Spectrum al CIFB. Apuntes para una historia". En: MARÍ, B.; RIBALTA, J.; ZELICH, C. Centre Internacional de Fotografia de Barcelona (1978-1983). Barcelona: MACBA, 2012, p. 283-297.

RICHON, Olivier. "Pensando las cosas". En: GREEN, D. (ed.). ¿Qué ha sido de la fotografía? Barcelona: Gustavo Gili, 2007, p. 77-87.

SALVADOR BENÍTEZ, Antonia (coor.). Patrimonio fotográfico. De la visibilidad a la gestión. Gijón: Trea, 2015.

SILVESTRE GARCÍA, Laura. "Los espacios expositivos y la política museística en la Comunidad Valenciana en los últimos 30 años". En: DE LA CALLE, R. (coord.). Los últimos 30 años del arte valenciano contemporáneo (I). Valencia: Real Academia de Bellas Artes de San Carlos, 2012, p. 32-53.

VEGA, Carmelo. Fotografía en España (1839-2015). Historia, tendencias, estéticas. Madrid: Cátedra, 2017.

ZELICH, Cristina (com.). Lisette Model. (Exposición celebrada en Madrid, Fundación Mapfre, del 23-09-2009 al 10-01-2010 y París, Jeu de Palme, del 09-02-2010 al 06-06-2010). Madrid: Fundación Mapfre, 2009.

ZELICH, Cristina. La fotografia creativa a Catalunya, 19731982. Barcelona: La Virreina. Centre de la imatge, 2018.

\section{Webgrafía}

ESPAI VISOR. "Historia", s/f (en línea). En: <http://espa visor.com/historia/> (Fecha de consulta: 13-02-2019).

GALERÍA MAX ESTRELLA. "Duane Michals". Nota de prensa, 2001 (en línea). En: <http://www.maxestrella. com/exposicion/duane_michals/notas_de_prensa.html> (Fecha de consulta: 02-04-2019).

MACBA. "Xavier Miserachs. 1937-1998", s/f (en línea). En: $<$ https://www.fotografiacatalunya.cat/es/catalogo/fotografos/xavier-miserachs> (Fecha de consulta: 23-032019).

MASDEARTE.COM. "Lisette Model, miradas sin miedo". 24-09-2009 (en línea). <http://masdearte.com/lisette model-miradas-sin-miedo/> (Fecha de consulta 04-042019). 
